\title{
Advanced Light Source Storage Ring RF System
}

\author{
Brian Taylor, Ken Baptiste, Henry Lancaster, and C. C. Lo
}

\author{
Accelerator and Fusion Research Division \\ Lawrence Berkeley Laboratory \\ 1 Cyclotron Road \\ Berkeley, California 94720
}

\section{Paper presented at the 1989 Particle Accelerator Conference in Chicago, Ilinois, March 20 to 23, 1989 DISCLAIMER}

\begin{abstract}
This report was prepared as an account of work sponsored by an agency of the United States Government. Neither the United States Government nor any agency thereof, nor any of their employees, makes any warranty, express or implied, or assumes any legal liability or responsibility for the accuracy, completeness, or usefulness of any information, apparatus, product, or process disciosed, or represents that its use would not infringe privately owned rights. Reference herein to any specific commerciel product, process, or service by trade name, trademark, manufacturer, or otherwise does not necessarily constitute or imply its endorsement, recommendation, or favoring by the United States Government or any agency thereof. The views and opinions of authors expressed herein do not necessarily state or reflect those of the United States Government or any agency thereof.
\end{abstract}

This work was supported by the Director, Office of Energy Research, Office of Basic Energy Sciences, Materials Sciences Division of the U. S. Department of Energy under Contract No. DE-AC03- 


\author{
Lawrence Bcrkeley Laboratory \\ University of California \\ Berkeley, California 94720
}

\section{Introduction}

The short electron bunch length (30ps design target) of the Advanced Light Source(ALS) stored beam is apable of exciting a wide spectrum of higher order mode(HOM) frequencies. Further, the small aperture and low cut off frequency of the beam enveloping components does not allow for transmission and consequent attenuation of the lower frequency HOM components.

The small cross section and divergence of the high brightness clectron beam will allow for more sophisticated high resolution experiments by synchrotron radiation users. A more stringent requirement on beam position stability results however. In this area transmitted mechanical vibration becomes a problem.

The ALS RF system splits $300 \mathrm{~kW}$ of CW $500 \mathrm{MHz}$ power between two single cell cavities. Compared to past practice this power rating is high. The use of only two cavities however has some advantages, it simplifies the waveguide feed system and releases room in straight sections for insertion devices, more important it reduces HOM and beam impedance problems.

\section{General Arranoement of the RF System}

Figure 1 shows the basic RF system in diagrammatic form. Table 1 lists the important parameters. Apart from the cavities and the special waveguide components, associated with HOM countermessures, all components are conventional catalog items. Conventional covity tuning setvos and amplitude feedback systems will be fitted.

$\begin{array}{lcc}\text { Beam Energy(GeV) } & 1.5 & 1.9 \\ \text { Frequency(MHz) } & 499.654 & 499.654 \\ \text { Beam Current(mA) } & 400.0 & 400.0 \\ \text { Two Crvity System Totals } & & \\ \text { Transit Time Factor(T) } & 0.683 & 0.683 \\ \text { Peak Effective Volts, YpT(MV) } & 1.5 & 1.5 \\ \text { Shunt Impedance, 22. L(Mohms) } & 16.0 & 16.0 \\ \text { Dissipation(kW) } & 140.0 & 140.0 \\ \text { Power Through Windows(kW) } & 210.0 & 286.0 \\ \text { Waveruide Losues(dB) } & 0.3 & 0.3 \\ \text { Circulator Lose(dB) } & 0.1 & 0.1 \\ \text { Radiated Power } & 37.0 & 94.0 \\ \text { Bending Magnets(kW) } & 30.0 & 50.0 \\ \text { 8 Undulators, 2 Wigglers(kW) } & 2.0 & 2.0 \\ \text { Parasitic Mode Lose(kW) } & 221.0 & 302.0 \\ \text { Required Amplifier Power(kW) } & & \end{array}$

Table 1, Slorage Ring RF Parameters

As yet the $300 \mathrm{~kW}$ amplifier tube has not been specified in detail, these items are available from a number of sources. The klystron solutions to this aeed would employ a tube basiclly designed for higher power, $600-800 \mathrm{~kW}$. These tubes could therefore be supplied to operate at a higher beam voltage than is strialy necesury to produce $300 \mathrm{~kW}$. An exercise will be undertaken to weigh the higher conversion efficiency, and consequent lower runing costs, of operating at higher voltage, against tube and powet supply costs.

\section{The RF Cavities and Windows}

Four identical single cell RF cavities are in process of construction for the ALS. One cavity for the booster synchrotron, two for the storage ring and one spare cavity. Prior to the final assembly of the storage ring cavities the design will be tested with a power source capable of $40 \mathrm{~kW} \mathrm{CW}$ or $60 \mathrm{~kW}$ long pulse ( $500 \mathrm{~ms}$ at 50 percent duty cycle).

The single cell toroidal cavities [1] will be fabricated from components precision machined from solid copper and joined by vacuum brazing. Cooling passages, needed to remove the dissipated $70 \mathrm{~kW}$ of power without generation of significant mechanical vibration will employ electroformed profiles.

An aperture type waveguide to cavity power input feed has been chosen for the cavity rather than the more usual loop coupler. The large unobstructed aperture of $15 \mathrm{~cm}$ diameter provides beneficial wideband coupling out of the cavity for HOM energy.

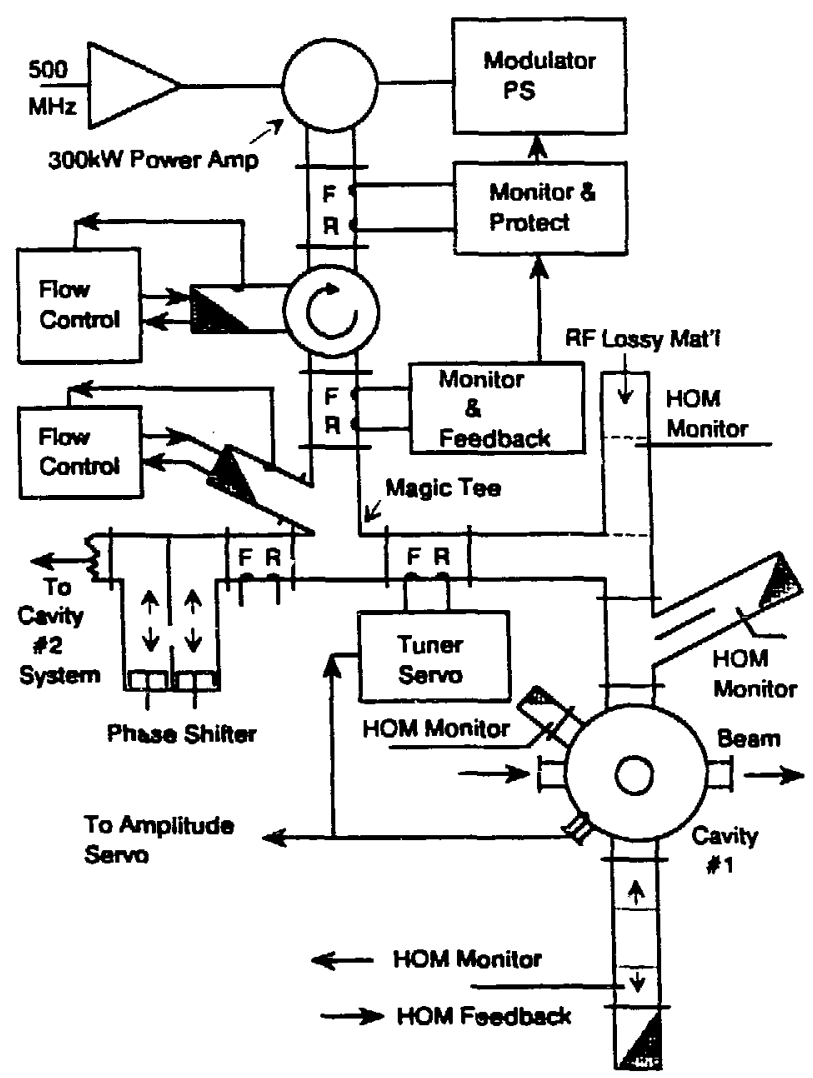

Figure 1, ALS Storage Ring RF System

In order to reduce the electric field in the ceramic due to the cavity contribution, a cylindrical window will be used; this arrangement also has the merit of placing the ceramic largely out of line of sight of the electron beam.

Initially a titanium coated window will be tested, provision has been made, however, to provide a metal blacked window [2].

\section{Mhz Water Load for Circulalor and Magic Tee}

For the majority of time when a storage ring is functioning correctly the power dissipated in the waveguide circulator or

This work was supported by the Director, Office of Energy Research, Office of Basic Energy Sciences, Matcrial Scicnces Division, of the U.S. Department of Energy under Contract No. DE-ACn3-76SF00098. 
isolator and the magic tee balance loads is very small. The loads are required to protect the system against high VSWR under fault or test conditions.

It is normal practice to employ coaxial type loads and to continually sirculate a high volume of water at high pressure, irrespective of the actual RF input to these loads. During normal stored beam conditions the mechanical vibration noise from these systems can be a nuisance to experimenters. Running large pumps continually is expensive in terms of power and maintenance costs.

The ALS water load systems are being designed to operate on a demand cooling system in which circulation or full creulation is triggered by detection of a significant power input or water temperature rise. A demand for increased load dissipation will almost certainly coincide with a "no beam" or "beam lost" situation, experimenters will thus not be inconvenienced. The preliminary design is based on the use of water wedge WR1800 waveguide loads.

Due to the substantial volume of water held in the load under static condition ample time is available to establish the flow. Indications are that the waveguide load system is cheaper than the coaxial equivalent, this price difference may, howcver, bc neutralized by more complex waveguide connections to the loads which have limitations on orientation.

\section{Higher Order Mode Countermeasures}

The philosophy of the ALS RF system HOM countermcasures is initially to provide:

\section{Good comprehensive diagnostic facilities.} cavity.

2 Effective wideband HOM absorbtive systems on each

3. Effective HOM absorbtive filters in the waveguide connections between cavities.

4. An overall system of woveguide assembly which facilitates experiment and change, once HOM problems and solutions arc determined, by beaming the systems. Such modification could include tuned HOM damping devices and the injection of active feedback.

The system for one cavity is shown in figure 2 , the basic systcm was pioneered at the Daresbury SRS [3]. The absorber arms of the $H$ plane and $E$ plane tee filters and the HOM transparent cavity matcher bucket all employ the same principle. A standard section of WR1800 waveguide has a central bilurcating conducting sheet, this short circuits the normal waveguide $E$ field, and transforms the single waveguide into two 9 inch by 9 inch guides.

This arrangement looks to the connecting WR1800 waveguide like a short circuit at $500 \mathrm{Mhz}$. Higher frequencies, not beyond cutoff are, however, transmitted.

In the system of figure 1 it will be noted that the coupling path between the two cavities is attenuated by two sets of $\mathrm{E}$ plane and H plane filters.

A volume arranged behind the two 9 inch by 9 inch waveguides remote from the point of $500 \mathrm{Mhz}$ reflection provides and ideal HOM monitoring, absorbing or controlled reflection point. Isolation from the $500 \mathrm{Mhz}$ power at this point will also allow rf power to be injected to excite cavity higher order resonances for feedback purposes. (e.g (c) in Figure 2)

The volume behind the bifurcated bucket of the cavity matcher is of particular convenience, and in the ALS design bolt-on variations of terminating devices will be facilitated.

Figure 2 illustrates some possible variations of these attachments.

(a) Is the normal tesistive absorbing terminalion. (b) Allows for the controlled ieflection of all components and therefore optimization of power transfer from the cavity of a single selected HOM component or band of components.

(c) Allows optimization of the coupling out from the cavity of two components of differing frequencies.

(d) Is designed to sweep the resonant frequencics of the waveguide termination, thereby "pulling" the coupled cavity resonances to "spoil" the buildup of instabilitics.



Figure 2, ALS Cavities HOM Approach

\section{References}

[1] C.C. Lo and B. Taylor, "Computer Aided Studics of the ALS 500Mhz StorageRing Cavity", this conference

[2] D.M. Dykes, T. Garvey, D.G. Poole and B. Toylor, "SRS RF Cavily Windows", IEEE Trans. Nuclan Science Vol. 32, 1988, Page 28100

[3] D.M.Dykes and B. Taylor, "Further Development of the SRS RF System", Proc. IEEE Accelerator Conference, Washington, 1987, Page 1940 